\title{
DERIVING INFLATION EXPECTATIONS FROM NOMINAL AND INFLATION-INDEXED TREASURY YIELDS*
}

May 16, 2000

\author{
Brian Sack \\ Division of Monetary Affairs \\ Board of Governors of the Federal Reserve System \\ Washington, DC 20551
}

\begin{abstract}
This paper derives a measure of inflation compensation from the yields of a Treasury inflation-indexed security and a portfolio of STRIPS that has similar liquidity and duration as the indexed security. This measure can be used as a proxy for inflation expectations if the inflation risk premium is small. The calculated measure suggests that the rate of inflation expected over the next ten years fell from just under 3\% in mid-1997 to just under $13 / 4 \%$ by early 1999 , before rising back to about $2 \frac{1}{2} \%$ by the beginning of 2000. This variation is more extensive than would have been expected from a simple model of inflation dynamics or from a survey measure of long-run inflation expectations.
\end{abstract}

\footnotetext{
* The author thanks James Clouse, Bill English, Norman Morin, Bill Nelson, Vincent Reinhart, and Dan Sichel for helpful comments. Correspondence can be directed to the address above or to brian.p.sack@frb.gov. The opinions expressed are those of the author and do not necessarily reflect the views of the Board of Governors of the Federal Reserve System or other members of its staff.
} 


\section{Introduction}

The U.S. Treasury began issuing inflation-indexed securities in January 1997. ${ }^{1}$ These securities--often referred to as TIPS (for Treasury inflation-protected securities)--have coupon and principal payments that are adjusted in line with (one measure of) the price level. This indexation compensates investors for the amount of inflation realized before payments on the security are made, so that the yield on an indexed security represents the real return (measured in terms of the amount of goods and services that can be purchased) that the investor can earn by holding the security to maturity.

By purchasing inflation-indexed securities, investors can protect themselves against the possibility that an unexpected rise in inflation will erode the real return realized on a nominal Treasury security, a protection that some investors might find appealing. Indeed, providing investors with a more complete set of financial instruments was cited by the Treasury as one of the motives for issuing indexed debt. ${ }^{2}$ The Treasury also hoped to reduce its borrowing costs by assuming the risks associated with unforeseen changes in inflation, since investors may demand a higher expected return on nominal Treasury securities as compensation for bearing that risk.

An ancillary benefit of issuing inflation-indexed securities, some have argued, is that the yields on those securities provide a measure of market expectations of real interest rates. Moreover, by comparing the yields of indexed securities to those of nominal Treasury securities, one can derive a reading of inflation compensation, or the component of the nominal yield that investors require to offset expected future inflation and the associated risks. In principle, such measures of inflation compensation could be used as proxies for inflation expectations, particularly if the inflation risk premium is low.

In fact, market participants often focus on one particular measure of inflation compensation--the difference between the yields of an inflation-indexed security and an on-the-run nominal security. ${ }^{3}$ This measure is frequently compared with market participants' expectations of future inflation to gauge the relative value of nominal and indexed securities. However, this yield

\footnotetext{
${ }^{1}$ For an overview of the Treasury's inflation-indexed debt program, see Wilcox (1997).

${ }^{2}$ See, for example, the comments by Robert Rubin at a Treasury press conference on January 21, 1997 announcing the first auction of inflation-indexed securities.

${ }^{3}$ On-the-run securities are the most recently issued security in each maturity class.
} 
spread has several shortcomings as a direct measure of expected future inflation. In particular, there are large differences between the liquidity of the nominal and indexed securities and between the patterns of their coupon and principal payments. These differences can importantly influence the yield spread between the securities for reasons unrelated to expected future inflation.

This paper derives an alternative measure of inflation compensation that addresses these shortcomings by creating a portfolio of Treasury STRIPS that has comparable liquidity to the inflation-indexed security and exactly replicates the pattern of its expected payments. The inflation compensation of that portfolio should more closely reflect the level of inflation anticipated by market participants. As a result, this new measure may be more appropriate for the numerous applications of a market-based measure of inflation expectations. For example, policymakers could use such a measure as a source of information about the markets' outlook for inflation and the impact of monetary policy decisions on that outlook. Market participants also might find such a measure to be more informative for assessing the relative value of nominal and inflation-indexed Treasury securities and for decomposing nominal interest rate risk into its real and inflation-related components.

The calculated measure of inflation compensation suggests that the rate of inflation expected over the next ten years fell from just under 3\% in mid-1997 to just under $13 \%$ by early 1999, before rising back to about $2 \frac{1}{2} \%$ by the beginning of 2000 . As discussed below, this variation is more extensive than would have been expected from a simple model of inflation dynamics or from a survey measure of long-run inflation expectations. The analysis also investigates higher frequency movements in the inflation compensation measure, finding that inflation compensation has responded significantly to macroeconomic news that might affect the outlook for inflation.

The paper begins by first describing the information contained in the spread between nominal and indexed yields. The proposed measure of inflation compensation based on STRIPS and TIPS is then derived, and its advantages relative to other measures are discussed. The paper then explores the behavior of the derived measure, first by comparing it to alternative measures of long-run inflation expectations, and then by estimating its response to macroeconomic news. Lastly, the analysis is extended to investigate the term structure of inflation compensation. 


\section{Measuring Expected Inflation}

This section begins by broadly describing the concept of inflation compensation and its correct interpretation. The measure of inflation compensation based on STRIPS and TIPS is then derived and discussed in detail.

\subsection{Inflation Compensation and Expected Inflation}

The yield on an inflation-indexed security represents the real return that the investor could realize by holding the security to maturity. In nominal terms, the investor earns this real return plus additional compensation for any inflation realized over the life of the security. Specifically, the principal value of the indexed security is adjusted daily so that its change over the current month equals the change in the non-seasonally adjusted overall Consumer Price Index for all urban consumers (CPI) observed between the third and second preceding calendar months (the minimum lag possible given the timing of the CPI data release) ${ }^{4}$ If the average rate of inflation is positive, the principal amount of the indexed security generally rises over its maturity horizon. Coupon payments are determined as a percentage of the indexed principal, so that they too increase at the rate of inflation. ${ }^{5}$

Because of this indexation, the total nominal return realized from holding an indexed security to maturity is equal to its yield plus the cumulative (lagged) amount of CPI inflation. By comparison, the total nominal return realized by holding a nominal Treasury security to maturity is simply equal to its yield. That yield embeds the return that the investor demands to compensate him for expected future inflation and the risk associated with that inflation. The spread between the yield on a nominal Treasury security and that on an inflation-indexed security represents the break-even rate of inflation, or the rate of inflation that would equalize the total returns of the two securities if it were realized over their remaining maturities. ${ }^{6}$ This rate of inflation is also

\footnotetext{
${ }^{4}$ The Treasury, however, puts a lower bound on the cumulative adjustment to the principal. In the event that consumer prices decline over the maturity of the security, the principal of the security at maturity will not be adjusted downward. ${ }^{5}$ Holders of indexed securities are taxed on the inflation adjustment in addition to the coupon payment. This approach makes the taxation of indexed securities comparable to that of nominal securities, on which the inflation compensation embedded in the coupon rate is taxed.

${ }^{6}$ More precisely, the break-even inflation rate is given by $((1+i / 2) /(1+r / 2))^{2}-1$, where $i$ is the nominal yield and $r$ is the TIPS yield, which is approximately equal to the difference in yields $i-r$.
} 
often referred to as the inflation compensation embedded in the yield of the nominal security.

To the extent that investors in fact demand similar expected returns on the nominal and indexed securities, inflation compensation will more closely represent the anticipated level of inflation. However, the expected returns on the securities likely differ for a number of reasons, including:

- The inflation risk premium embedded in nominal yields

- Differences in the impact of the expected path of real interest rates arising from differences in the duration of the securities

- Differences in the amount of real interest rate risk arising from differences in the duration of the securities

- Differences in the liquidity of the securities

Each of these factors is discussed in turn below, particularly in reference to the inflation compensation of nominal on-the-run securities--the measure that is most frequently discussed by market participants. ${ }^{7}$

The most obvious reason for the expected returns to differ is that an indexed security offers the investor protection against unanticipated changes in inflation, while a nominal security does not. Because investors might be compensated for bearing inflation risk, the yield on the nominal security may include an inflation risk premium. If this risk premium is positive, as is often assumed, inflation compensation will exceed the expected rate of inflation.

The expected returns on the securities may also differ because of differences in the patterns of their payments (and hence in their durations). In particular, the indexed security has payments that are more back-loaded than those of a nominal security with similar maturity. For example, a ten-year nominal note with a coupon rate of $6 \frac{1}{2} \%$ makes semiannual nominal coupon payments of $\$ 3.25$ and a principal payment of $\$ 100$. By comparison, if the rate of inflation is 3\%,

\footnotetext{
${ }^{7}$ One factor left out is differences in the "convexity premium" on the two securities. The convexity premium arises because for a given level of the yield, an increase in the volatility of the yield increases the expected return to the holder of a bond. For real interest rate volatility, this effect is greater for the indexed security, because its payments are more back-loaded. On the other hand, volatility of inflation increases the return on the nominal security without changing that
} 
a ten-year indexed security with a coupon rate of $4 \frac{1}{4} \%$ has coupon payments that gradually rise from $\$ 2.13$ to $\$ 2.82$ and a principal payment of over $\$ 132$. Expressed in real terms, the payments on the indexed security are fixed, while those of the nominal security decline over its maturity as inflation erodes the value of its nominal payments. The nominal security therefore has a shorter duration with respect to real interest rate changes than the indexed security.

The difference in the duration of the securities affects their expected returns in two ways. First, the difference in the durations implies that expected future real interest rates at various horizons are weighted differently in determining the yields on the two securities. Hence, if the real interest rate were expected to vary over the maturity of the securities, investors would not demand the same return on the nominal and indexed securities (as long as expected inflation does not equal zero). Second, the nominal and indexed securities would have different amounts of real interest rate risk, also causing their expected returns to differ.

The final reason that the expected returns may not be equal is that the liquidity of the nominal and indexed securities may differ. This consideration is particularly important in the case of the on-the-run nominal securities, whose liquidity is typically much greater than that of off-therun securities, owing to the extensive use of on-the-run securities in hedging and other tradingintensive investment activities. ${ }^{8}$ Because some investors value this greater liquidity, yields on onthe-run Treasury securities are often lower than yields on off-the-run Treasury securities with similar maturities. Inflation-indexed securities have liquidity levels that are closer to off-the-run nominal securities. As a result, yield spreads relative to the on-the-run issues typically understate inflation expectations.

Together, these differences complicate the process of reading inflation expectations from the yield spread between nominal and indexed securities, particularly using on-the-run nominal securities.

\footnotetext{
on the indexed security.

${ }^{8}$ See Fabozzi and Fleming (2000) and Dupont and Sack (2000) for additional details about liquidity and other
} 


\subsection{STRIPS/TIPS Measure of Inflation Compensation}

To address some of the issues raised above, this section computes an alternative nominal benchmark that more effectively matches the payment stream of the indexed security and has comparable liquidity. In particular, a measure of inflation compensation is computed for a nominal "security" created from a portfolio of Treasury STRIPS. ${ }^{9}$ For a given level of inflation, the increasing structure of coupon and principal payments of an indexed security can be calculated, and a portfolio of (smoothed) STRIPS can be generated that will exactly match those payments. The measure of inflation compensation is then determined as the inflation rate at which the replicating portfolio of STRIPS has the same value as the indexed security.

More specifically, the value of the indexed security is determined by the present discounted value of the nominal payments on that security. If the rate of inflation is constant (and, for simplicity, the first coupon payment is six months away), the price of the indexed security would be given by:

$$
P_{t}(N)=\sum_{i=1}^{2 N} c \cdot(1+\pi)^{i / 2} \cdot d_{t}(i / 2)+100 \cdot(1+\pi)^{N} \cdot d_{t}(N),
$$

where $N$ is the maturity of the security in years, $c$ is the coupon rate for the indexed security, $\pi$ is the rate of inflation, and $d_{t}(n)$ is the discount function, which measures the value of a $\$ 1$ payment made $n$ years from now.

In the exercise that follows, the discount function is calculated from yields on Treasury STRIPS. To do so, a smoothed zero-coupon yield curve is estimated based on the yields of those STRIPS derived from the coupon payments of notes and bonds. ${ }^{10}$ The estimated yield curve is then used to calculate the prices of zero-coupon securities maturing at the time of the coupon and principal payments of the indexed security--the discount function from equation (1). Alternatively, the discount function could have been estimated from off-the-run notes and bonds rather than

\footnotetext{
characteristics of the Treasury market.

${ }^{9}$ For a description of the STRIPS market and their pricing relative to Treasury notes and bonds, see Jordan, Jorgensen, and Kuipers (2000).

${ }^{10}$ The smoothing technique used is that from Fisher, Nychka, and Zervos (1995), applied using the software described in Fisher and Zervos (1996). Using a smoothed yield curve rather than actual STRIPS quotes allows us to value the discount function at maturities that exactly match the payments on the indexed security and removes some idiosyncratic variation in the yields of individual STRIPS.
} 
STRIPS. Using coupon STRIPS appears to have some advantages, however, partly because there are few off-the-run notes or bonds with maturities bracketing ten years (the maturity of the most liquid inflation-indexed security). ${ }^{11}$

Given the necessary values for the discount function and the observed price of the indexed security, equation (1) is used to solve for the inflation compensation measure $\pi$. Note that the right-hand side of equation (1) is simply the value of a portfolio of STRIPS with a weight of $c \cdot(1+\pi)^{n}$ for the STRIP maturing in $n$ years. Thus, the inflation compensation measure is the constant rate of inflation at which the value of the indexed security equals that of a portfolio of STRIPS that matches its expected payments. ${ }^{12}$

By matching the expected payments of the indexed security, the STRIPS portfolio should be influenced by the expected path of real interest rates and by the amount of real interest rate risk in the same manner as the indexed security, making their values more similar. In addition, the portfolio of STRIPS has a level of liquidity that is more comparable to the indexed security than that of an on-the-run nominal security, thereby reducing any distortions to the measure arising from the premium paid for more liquid securities.

That said, the STRIPS/TIPS measure will still be affected by the inflation risk premium. Removing the inflation risk premium would require a number of assumptions about the amount and price of inflation risk, which is beyond the purpose of this paper. One concern, however, is that the inflation risk premium of the STRIPS portfolio may be more variable than that of the onthe-run securities. The reason is that when inflation rises, the portfolio shifts its weighting toward longer-term STRIPS, which are often thought to have a larger inflation risk premium. The STRIPS-based measure therefore is most appropriate when the inflation risk premium is relatively small.

\footnotetext{
${ }^{11}$ For more details about the use of STRIPS for estimating the Treasury yield curve, see Sack (2000).

${ }^{12}$ Note that this portfolio itself depends on the rate of inflation compensation, and so the composition of this portfolio changes over time.
} 


\subsection{Empirical Results}

The methodology described above is applied to the most recently issued ten-year indexed security to derive the inflation compensation measure over that horizon, which is shown by the thick line in Figure 1. For comparison, the figure also shows the yield spread between the on-therun nominal ten-year note and the ten-year indexed security. The two measures of inflation compensation generally move in a very similar manner. Indeed, the correlation of their daily changes is 0.97 .

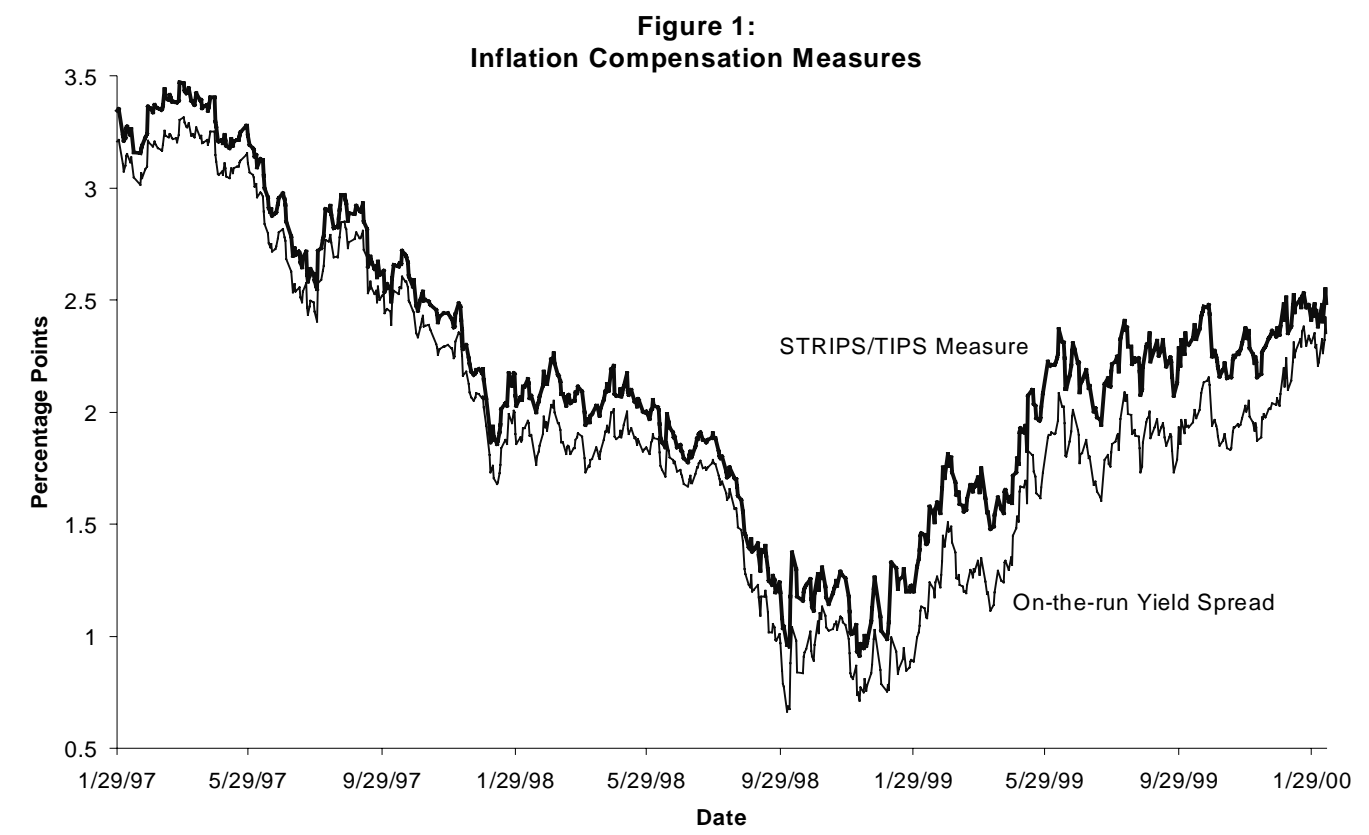

However, the STRIPS/TIPS measure is greater than the on-the-run spread throughout the sample, primarily because of the liquidity premium embedded in the on-the-run yield. Moreover, the difference between the on-the-run spread and the STRIPS/TIPS measure widened during the financial market turbulence in the fall of 1998, when investors' preferences for more liquid securities intensified. The flight to liquidity at that time caused the yields on on-the-run issues to drop well below those of less liquid Treasury securities, pushing the on-the-run yield spread as low as $0.68 \%$ on October 5 . The difference in the measures, shown by the thick line in Figure 2, increased to more than 30 basis points at that time and remained quite substantial over most of 1999, although it has recently narrowed.

Only a small portion of the difference between the two measures can be attributed to 
matching the payments of the inflation-indexed security, as shown by the thin line in the figure. ${ }^{13}$ This component typically accounts for less than 5 basis points of the difference in the measures and is often negative. The remainder of the difference can be attributed to more closely matching the liquidity of the indexed security, which has had a considerable impact because the premium on the on-the-run ten-year note was exceptionally large over the second half of the sample.

Figure 2:

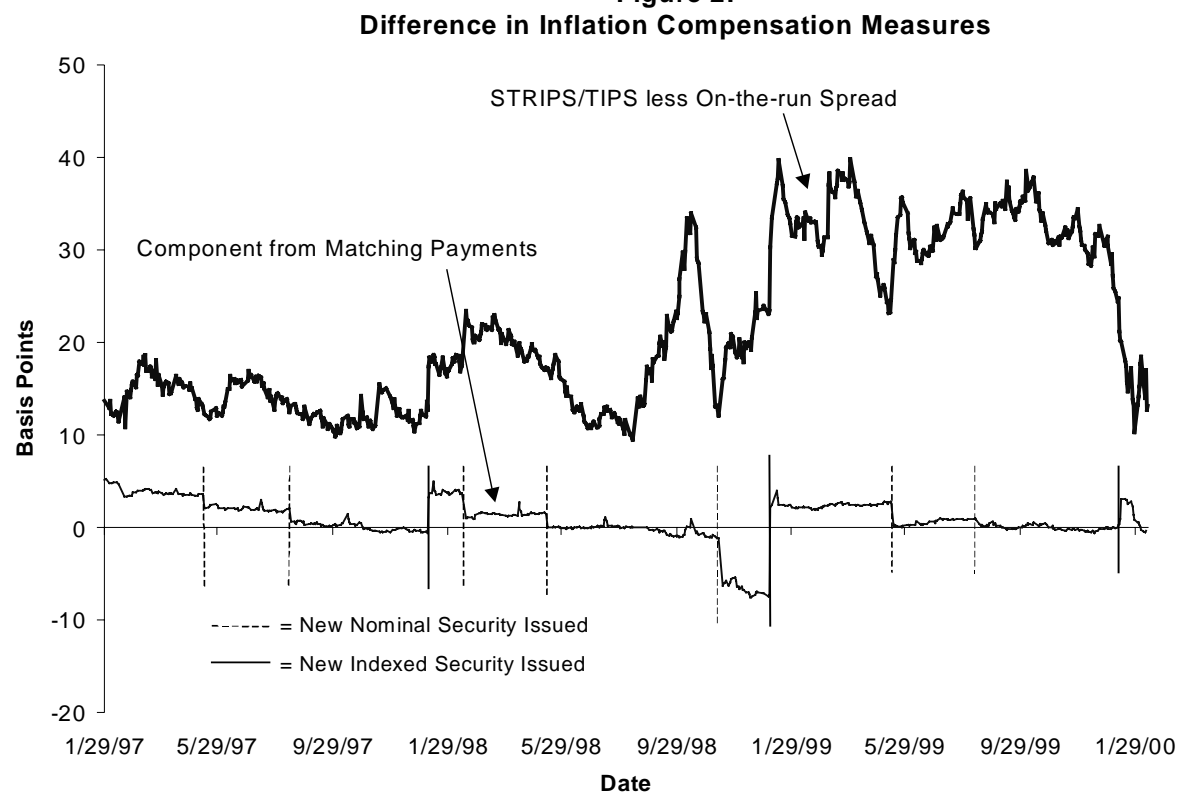

The limited impact of the payment-matching component reflects the fact that the durations of the on-the-run nominal security and the indexed security (and hence the STRIPS portfolio) are not that different in the current environment. On average over the sample, their durations were about $1 / 2$ a year apart. ${ }^{14}$ Based on the average slope of the STRIPS yield curve over the sample, an extra year of duration around these levels increases the yield by about 6 basis points, and hence the impact of the difference in durations has been limited.

The similarity in the durations of the ten-year securities reflects the low expected inflation rate and the (related) limited difference in their coupon rates. In addition, even though the backloading of the payments tends to increase the duration of the inflation-indexed security, the on-

\footnotetext{
${ }^{13}$ The impact of matching liquidity is based on the inflation compensation of a STRIPS portfolio that replicates the payments on the on-the-run ten-year nominal note, while the remainder can be attributed to matching duration.

${ }^{14}$ The duration of the indexed security, as used here, refers only to the timing of its nominal payments.
} 
the-run nominal security often has longer maturity because it is auctioned quarterly (with some reopenings), while only one new indexed security is issued each year. As a result, at times the duration of the nominal security was greater than that of the indexed security.

Of course, the current conditions limiting the impact of matching the payments of the indexed security could always change. Moreover, failing to match the payments of the indexed security has affected changes in the difference between the measures. As shown by the vertical lines in the figure, this component is strongly influenced by auctions. The STRIPS-based measure tends to increase relative to the on-the-run yield spread following auctions of the indexed securities, as the shift to an indexed security with greater duration is accounted for in the STRIPS portfolio but not in the on-the-run security. Similarly, the difference in the measures tends to decrease following the auctions of nominal securities, as the duration of the on-the-run security increases without a similar increase in the duration of the indexed security or the matching STRIPS portfolio.

\section{The Behavior of the Inflation Compensation Measure}

Figure 3 shows the STRIPS/TIPS measure of inflation compensation along with the rate of overall CPI inflation over the previous year. Over the first several months of the sample, the measure of inflation compensation remained between $31 / 4 \%$ and $31 / 2 \%$, above the range realized over the rest of the sample. However, it is possible that the measure was distorted near the beginning of the sample: Indexed yields may have been unusually low for a time because of the scarcity of indexed securities or because the market was simply going through a period of price discovery for this new type of security. Indeed, the inflation compensation measure moved below $3 \%$ within the first six months of the sample.

Subsequently, the inflation compensation measure fell from just under $3 \%$ in the middle of 1997 to about $2 \%$ by the middle of 1998 , coinciding with the considerable decline in the actual rate of inflation. One interpretation of these movements is that long-run inflation expectations fell as the current level of inflation moved lower. In addition, the inflation risk premium might have fallen as the outlook for inflation improved. 
The measure of expected inflation dropped more sharply during the financial market turbulence in the fall of 1998. Some of that decline may have reflected lower inflation expectations arising from the concern about the possibility of a financial crisis. However, a considerable portion of the decline was probably driven by the safe haven flows into Treasury securities, which seemed to affect yields on nominal Treasury securities, including STRIPS, by more than those on indexed securities. One reason is that investors appeared to increase their demand for liquidity. Even though STRIPS more closely match the liquidity of indexed securities than do on-the-run Treasuries, STRIPS are somewhat more liquid, and so the change in preferences likely pushed down the measure of inflation compensation at that time.

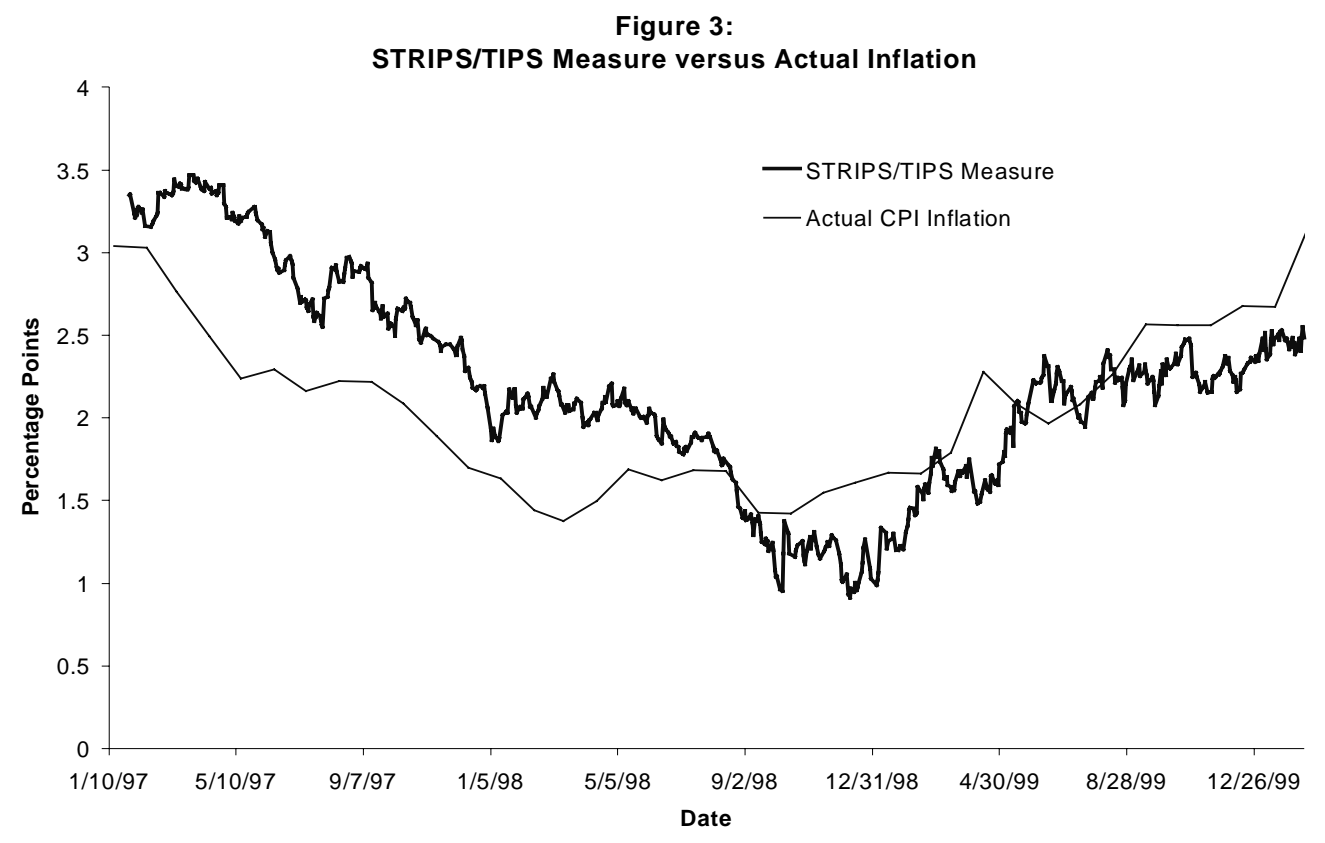

The concern about liquidity appeared to unwind some over the first several months of 1999 , likely contributing to the sharp rise in the measure of inflation compensation at that time. Inflation compensation continued to rise strongly through May, possibly reflecting an increase in inflation expectations that took place as the actual rate of inflation moved up and as concerns about the possible drag on the economy from the financial market turbulence waned. Since that time, inflation compensation has slowly drifted higher as realized inflation has continued to rise, with the measure reaching about $2 \frac{1}{2} \%$ by February 11, somewhat below the one-year CPI inflation rate through February, which topped $3 \%$. 


\subsection{Comparison to Alternative Measures of Inflation Expectations}

A perhaps surprising aspect of the results shown in Figure 3 is that the measure of inflation compensation appears to have responded considerably to movements in the current rate of CPI inflation, following the actual inflation rate lower through 1997 and into 1998 and then higher in 1999. As a result, inflation compensation has varied over a considerable range through the sample. This is the case even if one ignores the first six months of the sample and the episode from the fall of 1998 to early 1999, periods during which the inflation compensation measure may have been distorted by market influences other than changes in long-run inflation expectations. Leaving aside those periods, the inflation compensation measure fell from just under 3\% in mid1997 to just under $13 / 4 \%$ by early 1999 , before rising back to about $2 \frac{1 / 2}{2} \%$ by the beginning of 2000.

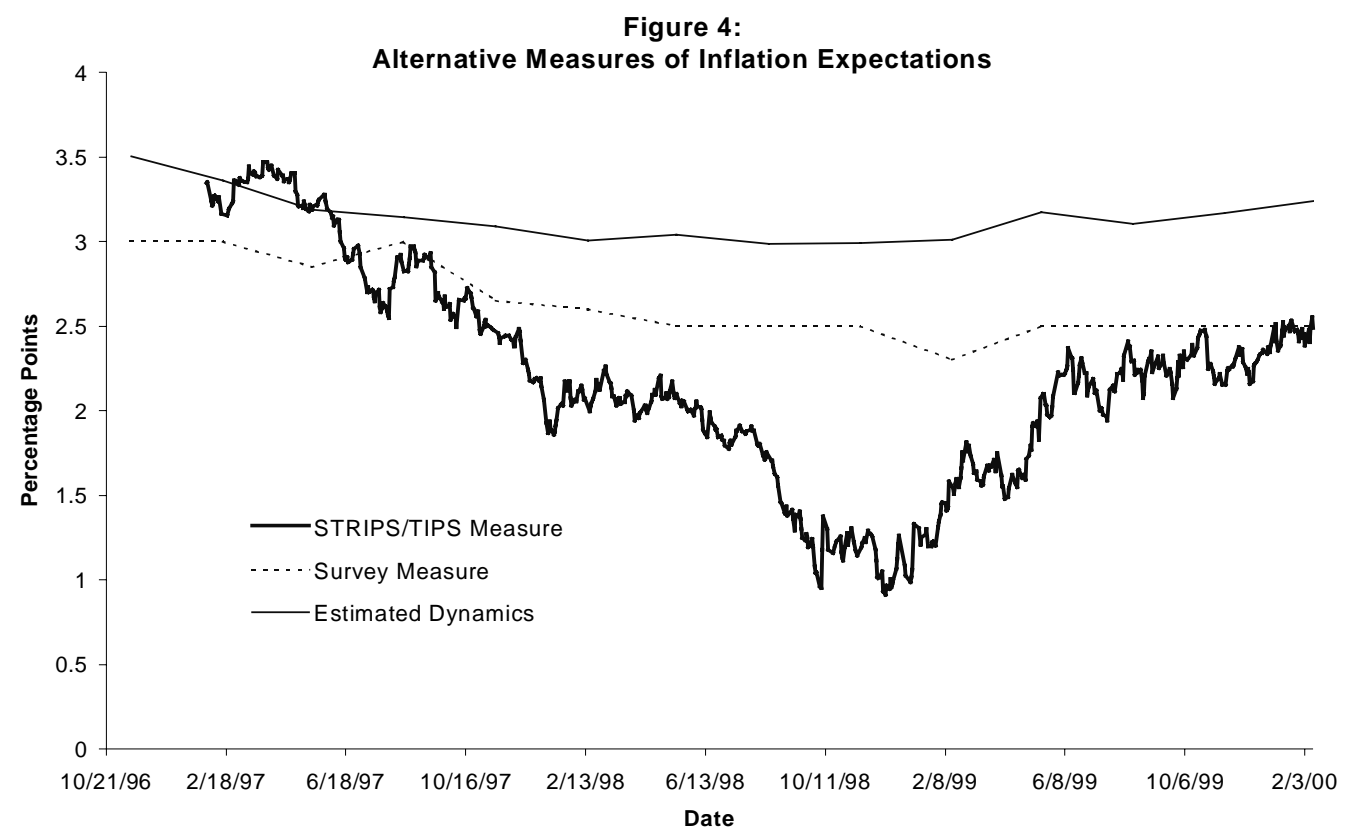

As shown in Figure 4, this range is about twice as large as the range observed for an alternative measure of long-run inflation expectations based on a survey conducted by the Federal Reserve Bank of Philadelphia (the dotted line). ${ }^{15}$ The survey reports the forecasts for the average

\footnotetext{
${ }^{15}$ One might be concerned that the measure of inflation compensation should place greater weight on the near-term inflation outlook than on the longer-run outlook because of the coupon payments on the securities, while the survey measure places equal weight on the entire forecast horizon. To this point, the relative weighting does not matter because expected inflation has been assumed to be constant. In section 4.1, expected inflation is allowed to vary, and the
} 
rate of CPI inflation over the next ten years from a large number of professional forecasters, with the median of those responses plotted in the figure. ${ }^{16}$ The survey measure has gradually declined from $3 \%$ to $2 \frac{1}{2} \%$ over the sample, dipping below $2 \frac{1}{2} \%$ only briefly.

The differences in the behavior of these two measures of inflation expectations can be evaluated by estimating the dynamic behavior of inflation over a longer time series. Table 1 presents estimates of the following univariate model of inflation dynamics:

$$
\Delta \pi_{t}=\beta_{0} \cdot \pi_{t-1}+\sum_{j=1}^{n} \beta_{j} \cdot \Delta \pi_{t-j}+\mu+\varepsilon_{t},
$$

where $\pi$ represents the quarterly percentage change in the overall CPI. ${ }^{17}$ The extent to which the measures of long-run inflation expectations should be affected by the current inflation rate will depend importantly on whether current changes in inflation are expected to be permanent or transitory. In the specification (2), the tendency for inflation to revert to a constant mean (equal to $-\mu / \beta_{0}$ ) would be captured by a significantly negative coefficient $\beta_{0}$. This coefficient is the basis for the augmented Dickey-Fuller (ADF) test of whether the inflation rate has a unit root. A finding that $\beta_{0}$ is not significant would suggest that inflation has a unit root, indicating that some portion of a current change in inflation would be expected to be permanent, which could generate a larger response of long-run inflation expectations to movements in the current inflation rate.

As shown in the first row of Table 1, over a sample from 1967 to 1999, the hypothesis that inflation has a unit root can be rejected, but only at the $10 \%$ significance level. However, it is unlikely that the process for inflation has been stable over this entire sample. Among other reasons, Clarida, Gali, and Gertler (2000) have found considerable differences between the characteristics of monetary policy during the 1960s and 1970s and that implemented in the 1980s and 1990s, including differences that might affect the average level of inflation. ${ }^{18}$

\footnotetext{
"hybrid" measure that is developed addresses this consideration correctly.

${ }^{16}$ An alternative survey conducted across households by the University of Michigan also indicates that expected inflation between 5 and 10 years out has remained in a narrow range, although with a slightly different pattern and level than the Philadelphia survey.

${ }^{17}$ The CPI series used in the analysis is the "experimental CPI" from 1967 to 1983, which adjusts for a change in the method used to measure homeowners' costs, spliced together with the published CPI after 1983. The BLS has recently made available a "research CPI" series that attempts to measure inflation in a methodologically consistent basis. I am instead using the published CPI figures since 1983 because the indexation is based on published data and because the research series includes methodological changes that had not yet been implemented over parts of the sample.

${ }^{18}$ The differences in the monetary policy rules found by Clarida, Gali, and Gertler (2000) would also likely affect the
} 
Table 1

\section{Dynamic Model of Inflation}

\begin{tabular}{cccccc}
\multicolumn{6}{c}{$\Delta \pi_{t}=\beta_{0} \cdot \pi_{t-1}+\sum_{j=1}^{n} \beta_{j} \cdot \Delta \pi_{t-j}+\mu+\mu^{>80}+\varepsilon_{t}$} \\
\hline$n$ & $\beta_{0}$ & $\Sigma \beta_{j}$ & $\mu$ & $\mu^{>80}$ & $R^{2}$ \\
\hline 7 & -.163 & .267 & .792 & -- & .20 \\
& $(-2.77)$ & & $(2.53)$ & & \\
7 & -.208 & .236 & 1.431 & -.650 & .23 \\
& $(-3.40)$ & & $(3.41)$ & $(-2.25)$ & \\
\hline
\end{tabular}

\footnotetext{
Quarterly CPI inflation from 1967:1 to 2000:1 as described in footnote 17 . This series is adjusted to remove the effects of recent methodological changes for the estimation. Lag length chosen by general-to-simple reduction based on a likelihood ratio test. Critical values under the null hypothesis of a unit root, calculated by bootstrap: Row 1: -3.51 at $1 \%$ significance level, -2.88 at $5 \%$, and -2.57 at $10 \%$ Row 2: -3.96 at $1 \%$ significance level, -3.36 at $5 \%$, and -3.05 at $10 \%$
}

To account for possible changes in the behavior of inflation, equation (2) is modified to allow for a shift in the long-run rate of inflation after 1980 by allowing a change in the constant term $\mu^{>80}$ in the later sample. Estimates of the modified equation (the second row of the table) provide stronger evidence that inflation follows a stationary, mean-reverting process, with its long-run mean shifting down by several percentage points in $1980 .{ }^{19}$ This shift, because it represents a permanent change in inflation, might have caused inflation to appear less stationary in the specification in row 1 of the table. Instead, inflation appears to have considerable persistence but to revert to a long-run mean of about 3\% since 1980 (measured under recent methodological changes). This mean reversion is consistent with the notion that the Federal Reserve implements monetary policy with an objective, among others, of maintaining a low level of inflation, thereby providing an anchor for the inflation rate in the long run.

Based on forecasts from the estimated dynamic process for inflation, and adjusting for methodological changes in the computation of the CPI over recent years, the expected average

\footnotetext{
persistence of inflation. The persistence of inflation over a more recent sample is discussed below.

${ }^{19}$ See Perron (1989) for an analysis of statistical tests to distinguish unit root processes from stationary processes with discrete shifts in their level or trend. The bootstrap routine used to calculate the critical values for row 2 of Table 1 is similar to the method described in that paper.
} 
inflation rate over the next ten years can be calculated as of each quarter over the sample. ${ }^{20}$ As shown by the thin line in Figure 4, the expected average inflation rate has remained in a narrow range, falling from about $3 \frac{1}{2} \%$ in early 1997 to just under $3 \%$ by late 1998 and rising modestly since that time. According to the results, the tendency for inflation to revert to a long-run mean strongly damps the impact of changes in the current inflation rate on its expected average over ten years. ${ }^{21}$ By this benchmark, the volatility of the inflation compensation measure is surprising. ${ }^{22}$ However, there may be several reasons to take the results from the estimated model cautiously. First, there is some disagreement in the academic literature about whether inflation has a unit root, with results differing depending on the samples, specifications, and measures used. Second, market participants surely use more complicated models than the univariate regression from Table 1 to predict inflation, such as models that incorporate additional variables and structure, or models that allow for shifts in regimes or in parameter values, all of which could possibly generate additional persistence in the inflation process.

The model estimated above may therefore be too restrictive as a benchmark for judging the behavior of the inflation compensation measure, particularly because of the strict assumption that the long-run inflation rate is known and constant. In fact, that assumption is called into question by the more recent inflation experience. Figure 5 plots both overall CPI inflation and core CPI inflation (which excludes its food and energy components) since the early 1980s. Of particular note, movements in core inflation over the range observed since 1984 have been very persistent, as it appears that policymakers have not been inclined to offset the gradual decline in core CPI inflation observed over recent years. At the same time, overall CPI inflation has shown a tendency to revert fairly strongly toward the core measure. Specifically, there have been several

\footnotetext{
${ }^{20}$ The Bureau of Labor Statistics has implemented a number of changes in recent years to remove upward bias in the measured CPI inflation rate. According to the 1999 Economic Report of the President, changes implemented since 1995 are estimated to have had the following cumulative effect on the CPI inflation rate by the year indicated: -.23 by $1997,-.44$ by $1998,-.64$ by 1999 , and -.68 by 2000 . In the results shown, market participants are assumed to steadily anticipate the coming methodological changes over the year before their implementation.

${ }^{21}$ Of course, if inflation is assumed to have a unit root, the results from the estimated model look more consistent with the inflation compensation measure, because some of the current changes in inflation feed through into long-run inflation expectations. This possibility is discussed below.

${ }^{22}$ It is possible that some of the volatility of the inflation compensation measure is driven by changes in the inflation risk premium, although it is doubtful that such changes are large enough to explain the considerable difference from the model results.
} 
large, transitory movements in energy prices over this sample, including shocks in 1986, in 1990, and in the past several years.

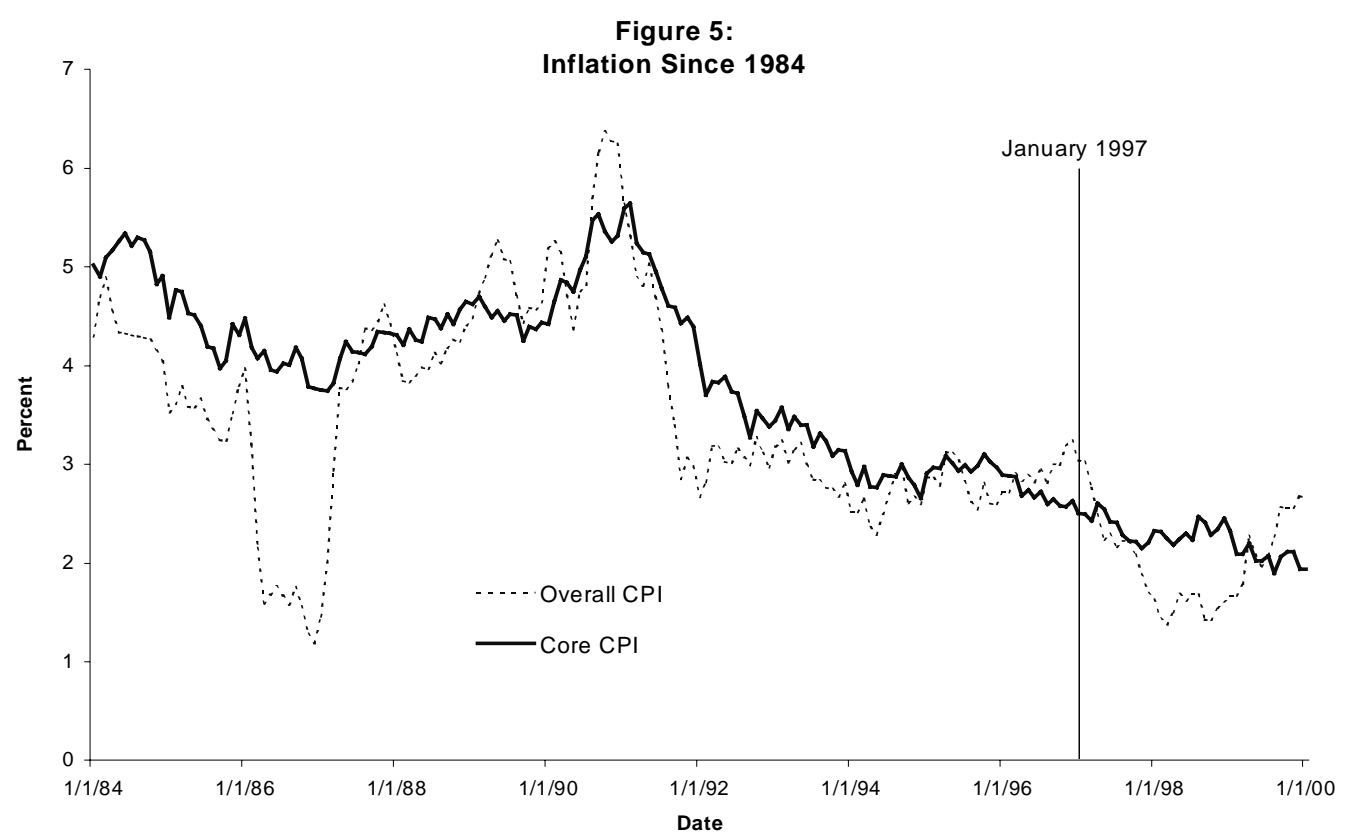

The persistent decline in core inflation over recent years suggests that the long-run outlook for inflation may have improved, which would not be captured in the estimated model from Table 1. Indeed, as of the end of the sample, the model predicts an average inflation rate that is greater than both the survey measure and the inflation compensation measure. The inflation compensation measure at the end of the sample is much closer to the core inflation rate, as would be expected if the decline in core inflation over recent years were perceived to be largely permanent.

Nevertheless, the extent to which the inflation compensation measure has varied is still somewhat surprising. The decline and subsequent rise in the measure through the first half of 1999 followed the pattern observed for overall CPI inflation, which was driven primarily by changes in energy prices. If those changes in energy prices were expected to be as transitory as they have been since 1984, the impact on the inflation compensation measure should have been limited. Interestingly, the inflation compensation measure has held fairly steady during the more recent run-up in the inflation rate, which has again been driven primarily by energy prices. In particular, the inflation compensation measure has remained in a fairly narrow range between $2 \%$ 
and $2 \frac{1}{2} \%$ since mid-1999, even as CPI inflation has increased by more than 1 percentage point to above $3 \%$ (see Figure 3).

\subsection{The Response of Inflation Compensation to Macroeconomic News}

To further assess the behavior of the inflation compensation measure, this section investigates the responsiveness of the measure to macroeconomic news that may contain information about the outlook for inflation. In doing so, this exercise exploits an important advantages of market-based measures of inflation expectations--that they are available on a timely basis, whereas survey measures are typically released only on a monthly or quarterly basis.

The reaction of yields to macroeconomic data releases should depend on the amount of news, or the surprise, contained in the release. In the following results, that news is measured by the difference between the released value of the macroeconomic variable and the expected value as measured by a survey conducted by Money Market Services about a week before the release. The results focus on six monthly macroeconomic news releases: overall CPI, core CPI, overall PPI, non-farm payrolls, retail sales, and the National Purchasing Managers (NAPM) survey of industrial conditions.

Table 2 shows the results from a regression of the daily change in the inflation compensation measure on the economic news. As shown in the last column, the inflation compensation measure has reacted significantly to many of the data releases over the sample, including news directly about CPI inflation as well as news about economic strength that might raise inflationary pressures.

The first two columns separately show the responses of nominal and indexed yields to the macroeconomic news. Although the inflation compensation measure is based on a (changing) portfolio of STRIPS, for simplicity the table reports the yield on the ten-year STRIPS. The results indicate that nearly all of the responsiveness of the inflation compensation measure has been driven by changes in the nominal yield. In particular, the nominal yield has reacted significantly to all of the news releases except the PPI, while the indexed yield has not reacted 
significantly to any of the news releases. ${ }^{23}$

Table 2

\section{Response of Ten-year Inflation Compensation and Treasury Yields to Economic News}

Table reports the reaction (in basis points) to a standard deviation change

to the surprise in the indicated variable (and the corresponding t-statistic)

\begin{tabular}{cccc}
\hline Variable & Nominal Yield & Indexed Yield & Inflation Comp. \\
\hline & & & \\
CPI & $2.8(2.76)^{* *}$ & $-0.4(-1.11)$ & $3.1(3.37)^{* *}$ \\
Core CPI & $3.2(3.21)^{* *}$ & $0.0(0.03)$ & $3.1(3.30)^{* *}$ \\
PPI & $-0.2(-0.17)^{*}$ & $-0.1(-0.34)$ & $-0.2(-0.20)$ \\
Payrolls & $2.0(1.86)^{*}$ & $0.5(1.29)$ & $1.4(1.57)$ \\
Retail Sales & $2.5(2.28)^{*}$ & $0.4(1.36)$ & $2.0(2.32)^{*}$ \\
NAPM & $3.2(3.27)^{* *}$ & $0.2(-0.61)$ & $2.5(3.43)^{* *}$ \\
& & & \\
\hline
\end{tabular}

Based on regression of change in inflation compensation or yield on day of news on the unexpected component of the news. New releases are monthly from 1997 to 1999. ${ }^{*}$ indicates significance at the $5 \%$ level, and ${ }^{* *}$ at the $10 \%$ level

Of course, one might expect the nominal yield to have a larger reaction, because most of these releases contain information about inflation in addition to real interest rates (and the two components would typically affect the nominal yield in the same direction). However, it is surprising that the exercise cannot detect a statistically significant reaction of the indexed yield to any of these news items, which surely contain information about the expected path of real interest rates. ${ }^{24}$ Moreover, it is implausible that almost all of the response of the nominal yield to these variables results from changes in inflation compensation. ${ }^{25}$ This finding suggests that one should be cautious in interpreting higher frequency movements in the inflation compensation measure.

\footnotetext{
${ }^{23}$ Indexed yields may show a perverse reaction to CPI surprises, especially to transitory surprises, because of the lag in the indexation. The reason is that the entire CPI release (which itself has about a one-month lag) affects the value of the payments on the indexed security, while only some portion of the release affects the outlook for inflation from today onward (and hence the yields at which those nominal payments are discounted).

${ }^{24}$ The insignificance of the response of the indexed yield could result from the lower liquidity of indexed securities. While lower liquidity does not necessarily make the yield less responsive, it might make the response more difficult to measure by allowing the indexed yield to deviate longer and farther from its fundamental value than would be possible for a more liquid security. In addition, the regressions involve only a limited number of data points.

${ }^{25}$ While the exercise finds the relative responses of nominal and indexed yields to be puzzling, it does not reach any conclusions about whether nominal yields are excessively volatile or indexed yields are excessively stable.
} 


\section{The Term Structure of Inflation Expectations}

Despite the advantages of the inflation compensation measure derived above, it has the shortcoming of assuming that expected inflation will remain constant over the life of the indexed security. This section relaxes that assumption under two different approaches.

\subsection{A Hybrid Approach}

The inflation compensation measure calculated above properly accounts for the shape of the nominal yield curve (equivalently, the shape of the discount function) under the assumption that the inflation rate is expected to be constant. However, this assumption may impose unrealistically simple dynamics for the inflation process, especially given that the current inflation rate would have to instantaneously jump to the long-run level.

An alternative approach is to incorporate the estimated persistence of inflation from the results in Table 1 to allow inflation to have a richer dynamic path in deriving the long-run level implied by nominal and indexed Treasury yields. This "hybrid" approach assumes that inflation will evolve from its current level according to the dynamic process specified in the second row of Table 1, only allowing the long-run mean of the process (the constant in the regression) to vary over time. ${ }^{26}$ The difference between nominal and indexed yields determines the long-run mean-that is, equation (1) is solved for the long-run mean, only allowing the rate of inflation to approach that mean gradually given its estimated persistence.

As an example, the hybrid measure stood almost $1 / 4$ percentage points lower than the constant inflation compensation measure (from section 3) near the end of the sample, reflecting the expectation that inflation would gradually decline from its current level to its long-run mean. However, this difference is among the largest observed between the two measures over the sample. In general, the long-run mean of the inflation process found under the hybrid approach has remained fairly close to the constant inflation compensation measure computed above. The reason is that, as previously shown in Figure 3, the inflation compensation measure has tended to follow the current rate of inflation, so that allowing for richer dynamics of inflation from its

\footnotetext{
${ }^{26}$ Of course, there is a logical inconsistency in that the persistence of inflation was estimated under the assumption of a constant mean, an assumption that is now being relaxed.
} 
current rate to its long-run rate has only a limited impact.

\subsection{Incorporating Additional Indexed Securities}

Because it is based on the information from only one indexed security, the inflation compensation measure calculated above could only determine one parameter of the inflation process--either the constant level of inflation under the original approach, or the long-run mean of the inflation process under the hybrid approach. This section incorporates information from additional outstanding indexed securities to allow expected future inflation to vary over different horizons.

If a full range of indexed securities were available, one could simply estimate a real discount function across all maturities and, by comparing it to the nominal discount function estimated from STRIPS, derive a complete term structure of inflation compensation.

Unfortunately, at this time there are only seven different indexed securities outstanding, with remaining maturities clumped around $2 \frac{1}{2}$ years, 7 to 10 years, and 28 to 29 years. As a result, this approach can only be implemented by imposing strong restrictions on the functional forms of the discount functions. ${ }^{27}$

While it may be difficult to estimate a complete term structure of inflation compensation, one can at least allow for discrete changes in inflation compensation across various maturities of outstanding indexed securities. The following exercise allows for shifts in inflation compensation at the maturities of recently issued indexed securities in each maturity class. In particular, the inflation compensation measure is first calculated for the five-year indexed note (with $21 / 2$ years remaining to maturity). Taking the result as the fixed level of inflation over that horizon, the tenyear indexed note (with 9 years remaining to maturity) is used to derive the level of inflation from $2 \frac{1}{2}$ to 9 years. The exercise is repeated once more for the thirty-year indexed bond (with 28 years remaining to maturity). The resulting term structure of inflation compensation as of January 7,2000 is shown in Table $3 .^{28}$

\footnotetext{
${ }^{27}$ This approach has been taken by McCulloch and Kochin (1998).

${ }^{28}$ This date was chosen instead of the end of the sample (February 11) because several announcements about potential changes in the supply of Treasury securities appear to have generated large declines in long-term yields over the last month of the sample.
} 
The term structure of inflation compensation on that date has a hump-shaped pattern, which is somewhat surprising. One might have expected a monotonically declining pattern, if inflation were expected to gradually decline from its current level of over $3 \%$ to its estimated long-run mean. In fact, inflation compensation from $2 \frac{1 / 2}{2}$ to 9 years and that from 9 to 28 years are very consistent with such expectations, but inflation compensation over the near-term is surprisingly low. One possibility is that the yield on the five-year indexed note is out of line with the other yields because the Treasury no longer issues those securities (and issued the outstanding security more than $2 \frac{1}{2}$ years ago). Moreover, inflation compensation at very long maturities has recently been affected by volatile movements in longer-term Treasury yields associated with announced changes in the supply of those securities. These considerations argue in favor of a measure that only uses the ten-year indexed note--the most actively traded indexed security.

Table 3

Term Structure of Inflation Compensation January 7, 2000

\begin{tabular}{cc}
\hline Time Horizon & $\begin{array}{c}\text { Inflation } \\
\text { Compensation }\end{array}$ \\
\hline $0-21 / 2$ years & 2.24 \\
$21 / 2$ to 9 years & 2.40 \\
9 to 28 years & 2.29 \\
\hline
\end{tabular}

\section{Conclusion}

Yields on nominal and indexed Treasury securities provide a potentially appealing source of information about inflation expectations, one that could be used as an alternative to survey measures and econometric estimates. Among its advantages, a market-based measure can provide readings of inflation expectations on a much more timely basis than survey measures and can account for structural shifts in the behavior of inflation to the extent that they are perceived by financial market participants.

This paper has described a methodology for deriving a measure of inflation expectations by constructing a portfolio of nominal STRIPS to be compared to the inflation-indexed security. 
The constructed portfolio has the advantage of matching the increasing payment structure of the indexed security and having a similar level of liquidity. As a result of these similarities, this measure should more closely reflect market expectations of future inflation, particularly if the inflation risk premium is low and the expected path of inflation does not vary too much. If inflation is instead expected to vary considerably over the remaining maturity of the indexed security, it may be more appropriate to use the "hybrid" measure, which allows inflation to evolve under its estimated dynamics from its current level to a long-run level determined by Treasury yields.

Through early 2000, the measure of inflation compensation derived from STRIPS and TIPS varied more extensively than a survey measure of inflation expectations. In addition, the historical behavior of inflation suggests that much of the movement in the actual inflation rate since 1997 should have been expected to be transitory, and therefore should have had only a limited impact on the inflation compensation measure. The more extensive variation in the measure could indicate that investors have expected recent changes in inflation to have a larger permanent component than historical norms would suggest. On the other hand, the differences between the STRIPS/TIPS measure of inflation expectations and those based on the historical behavior of inflation or surveys could lead some observers to question the usefulness of this measure. A final consideration is that the usefulness of the measure may be improving. Indeed, the most extensive variation in the measure took place through mid-1999, after which the measure has held fairly steady despite a considerable rise in the actual rate of inflation. Unfortunately, there is, as yet, insufficient data to allow a convincing assessment of the value of the derived inflation compensation measure as a predictor of future inflation. 


\section{References}

Clarida, Richard, Jordi Gali, and Mark Gertler. 2000. Monetary Policy Rules and Macroeconomic Stability: Evidence and Some Theory. Quarterly Journal of Economics 115, 147-180.

Dupont, Dominique and Brian Sack. 1999. The Treasury Securities Market: Overview and Recent Developments. Federal Reserve Bulletin 85, 785-806.

Fisher, Mark, Douglas Nychka, and David Zervos. Fitting the Term Structure of Interest Rates with Smoothing Splines. Finance and Economic Discussion Series Working Paper \#95-1, Board of Governors of the Federal Reserve System.

Fisher, Mark and David Zervos. 1996. YieldCurve. In H. Varian (ed.), Computational Economics and Finance: Modeling and Analysis with Mathematica. New York: SpringerVerlag.

Fabozzi, Frank J. and Michael J. Fleming. 2000. U.S. Treasury and Agency Securities. In F. Fabozzi (ed.), The Handbook of Fixed Income Securities: $6^{\text {th }}$ Edition. New York: McGraw Hill.

Jordan, Bradford D., Randy D. Jorgensen, and David R. Kuipers. 2000. The Relative Pricing of U.S. Treasury STRIPS: Empirical Evidence. Journal of Financial Economics 56, 89-123.

McCulloch, J. Huston and Levis A. Kochin. 1998. The Inflation Premium Implicit in the US Real and Nominal Term Structures of Interest Rates. Working Paper \#98-12, Ohio State University Economics Department.

Perron, Pierre. 1989. The Great Crash, the Oil Price Shock, and the Unit Root Hypothesis. Econometrica 57, 1361-1401.

Sack, Brian. 2000. Using Treasury STRIPS to Measure the Yield Curve. Mimeo, Board of Governors of the Federal Reserve System.

Wilcox, David W. 1997. The Introduction of Indexed Government Debt in the United States. Journal of Economic Perspectives 12, 219-227. 